\title{
Unifocalization of major aortopulmonary collateral arteries in pulmonary atresia with ventricular septal defect is essential to achieve excellent outcomes irrespective of native pulmonary artery morphology
}

\author{
Ben Davies, MRCS(Eng), PhD, ${ }^{a}$ Shafi Mussa, MA, MD, MRCS(Eng), ${ }^{a}$ Paul Davies, PhD, ${ }^{\text {b }}$ \\ John Stickley, BSc, ${ }^{c}$ Timothy J. Jones, MD, FRCS(CTh), ${ }^{a}$ David J. Barron, MD, MRCP, FRCS(CTh), ${ }^{a}$ and \\ William J. Brawn, FRCS, FRACS ${ }^{\mathrm{a}}$
}

\begin{abstract}
Objective: Pulmonary atresia with ventricular septal defect and major aortopulmonary collateral arteries is a complex lesion with a high rate of natural attrition. We evaluated the outcomes of our strategy of unifocalization in the management of these patients.
\end{abstract}

\begin{abstract}
Methods: From 1989 to 2008, 216 patients entered a pathway aiming for complete repair by unifocalizing major aortopulmonary arteries to a right ventricle-pulmonary artery conduit with ventricular septal defect closure. Where ventricular septation was not possible, definitive repair was considered to include pulmonary artery reconstruction and a right ventricle-pulmonary artery conduit or systemic shunt. Native pulmonary artery morphology was classified into confluent intrapericardial $(n=139)$, confluent intrapulmonary $(n=51)$, and nonconfluent intrapulmonary $(\mathrm{n}=26)$.
\end{abstract}

Results: A total of 203 patients $(85 \%)$ had definitive repair at a median age of 2.0 years. There was no statistically significant difference in survival after complete repair among the 3 morphologic pulmonary artery groups $(P=.18)$. A total of 132 patients $(56 \%)$ had complete repair with ventricular septal defect closure, as a single procedure in 111 patients and a staged procedure in 21 patients. Focalization of major aortopulmonary collateral arteries with proven long-term patency with the right ventricle was associated with a survival benefit compared with 14 patients in whom unifocalization was not possible and who had only systemic shunts. Overall survival was $89 \%$ at 3 years after definitive repair. During follow-up, 190 patients required 196 catheter reinterventions and 60 surgical reinterventions.

Conclusion: By using a strategy of unifocalization, intrapericardial pulmonary artery reconstruction, and right ventricle-pulmonary artery conduit, excellent long-term survival can be achieved in this group of patients even in the absence of native intrapericardial pulmonary arteries. (J Thorac Cardiovasc Surg 2009;138:1269-75)

\section{Supplemental material is available online.}

Pulmonary atresia with ventricular septal defect (VSD) and major aortopulmonary collateral arteries (MAPCAs) is a complex lesion that is estimated to occur in 10 of 100,000 liveborn infants and that has a high rate of natural attrition. ${ }^{1,2}$ Until recently, only a small proportion of infants with this condition would ultimately undergo complete repair, and the outcomes after surgical intervention were disappointing, ${ }^{3-5}$ with an estimated $20 \%$ chance of surviving to the age of 30 years. ${ }^{1}$

\footnotetext{
From the Departments of Cardiac Surgery, ${ }^{\mathrm{a}}$ Institute of Child Health, ${ }^{\mathrm{b}}$ and Cardiac

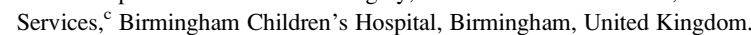

Received for publication April 26, 2009; revisions received July 2, 2009; accepted for publication Aug 9, 2009; available ahead of print Oct 21, 2009.

Address for reprints: Ben Davies, MRCS(Eng), PhD, Department of Cardiac Surgery,

Birmingham Children's Hospital, Steelhouse Lane, Birmingham B4 6NH, United

Kingdom (E-mail: ben davies@doctors.org.uk).

$0022-5223 / \$ 36.00$

Copyright (C) 2009 by The American Association for Thoracic Surgery

doi:10.1016/j.jtcvs.2009.08.011
}

In this group of patients, pulmonary arterial blood flow is provided by MAPCAs, which vary in number and origin, ${ }^{6-8}$ together with the heterogeneous presence of native central PAs. The management of MAPCAs and their incorporation into any definitive repair remains controversial. Without intervention, MAPCAs may stenose and occlude or alternatively induce pulmonary vascular disease as a result of overperfusion.

We believe a key determinant of long-term success is to maximize recruitment of lung segments, and definitive repair should include mobilization and incorporation of native MAPCAs into a reconstructed central and peripheral pulmonary arterial tree, closure of the VSD, and a right ventricle-pulmonary artery (RV-PA) conduit to establish continuity between the PA confluence and the RV. This may be achieved by single or multiple stages via sternotomy or thoracotomies to perform mobilization of MAPCAs, augmentation of hilar vessels, or systemic-to-pulmonary shunts. Such a strategy has been successfully used, ${ }^{9}$ yet is contrary to clinical practice undertaken by others. ${ }^{10}$

There remains little evidence that an aggressive surgical approach in this particular patient group confers any long-term survival benefits or functional advantage over 


$$
\begin{array}{ll}
\text { Abbreviations and Acronyms } \\
\text { CI }=\text { confidence interval } \\
\text { MAPCAs = } & \text { major aortopulmonary collateral } \\
& \text { arteries } \\
\text { OR } & =\text { odds ratio } \\
\text { RV-PA } & =\text { right ventricle-pulmonary artery } \\
\text { VSD } & =\text { ventricular septal defect }
\end{array}
$$

shunted patients, and most published data are limited to small surgical series with follow-up approaching 10 years. The objectives of the current study were to evaluate the outcomes of our policy that emphasizes MAPCA unifocalization together with intrahilar and intrapericardial PA reconstruction.

\section{MATERIALS AND METHODS}

The National Research Ethics Service, United Kingdom, considered this study to be a service evaluation and therefore did not require review by the National Health Service Research Ethics Committee. The data of all patients with pulmonary atresia, VSD, and MAPCAs who underwent surgical inter vention at Birmingham Children's Hospital, Birmingham, United King dom, between January 1, 1989, and July 31, 2008, were reviewed.

Patients with other intracardiac pathologies accompanied by MAPCAs were excluded from the study. A total of 237 patients entered a treatment pathway aiming for complete repair by unifocalizing major aortopulmonary arteries to an RV PA conduit with VSD closure. When ventricular septation was not possible, definitive repair was considered to include PA reconstruc tion and a limiting RV PA conduit or systemic pulmonary shunt. Of these 237 patients, complete follow up data were available for 216 (120 female), and this cohort was used for analysis.

\begin{abstract}
Assessment
Echocardiographic assessment was supplemented by cardiac catheter ization to delineate the pulmonary blood supply and the characteristics of the MAPCAs. Patients were classified into 3 morphologic subgroups according to the presence or absence of confluent native PAs within the pericardium and at the hilum of the lung. ${ }^{11}$ This spectrum extends in increasing order of complexity from confluent intrapericardial vessels, through absent intrapericardial but confluent intrapulmonary vessels, to absent intrapericardial and nonconfluent intrapulmonary vessels. The rel ative importance of each MAPCA was considered with a view to incor porating them into a definitive repair to maximize recruitment of at least 15 individual lung segments. The number of MAPCAs was assessed, and the patients were grouped categorically into less than 5 or more than 5 for the purposes of analysis.
\end{abstract}

\section{Surgical Approach}

The technical aspects of surgical intervention facilitated by hypothermic cardiopulmonary bypass with intermittent circulatory arrest have been described $^{11,12}$ and share several common features with techniques reported by other centers. ${ }^{9,13} 17$

\section{Follow-up}

Dates of definitive surgery were chosen as a common time point from which to derive follow up for all patients. Reintervention was defined as the time from definitive surgery to the first surgical or catheter based intervention because we considered that after such interventions the natural histories of individual patients were considered to be sufficiently disparate to preclude further useful analysis on a cohort basis.

\section{Statistics}

Data are presented as median with interquartile range or mean \pm standard deviation. Survival analysis was performed by the Kaplan Meier method, and data were compared using log rank and Wilcoxon tests. Multifactor analysis of risk factors for survival or death was performed by Cox propor tional hazards regression. Factors included in the analysis were age at defin itive surgery, gender, DiGeorge syndrome, native PA morphology, the number of MAPCAs, prior surgery at other centers, prior recruitment procedures, or creation of a central shunt or a peripheral shunt. Analyses were performed with SPSS 17.0 (SPSS UK Ltd, Woking, UK).

\section{RESULTS \\ Patient Characteristics}

A total of 216 patients (120 female) were identified. Native PA morphology was classified into confluent intrapericardial $(\mathrm{n}=139)$, confluent intrapulmonary $(\mathrm{n}=51)$, and nonconfluent intrapulmonary $(\mathrm{n}=26)$. A total of 123 patients had less than 5 MAPCAs, and 24 patients had more than 5 MAPCAs (69 patients missing information). Twenty-five patients $(11 \%)$ had clinically overt DiGeorge syndrome; genetic testing for 22q11 deletion was performed selectively after informed parental consent was obtained. Before definitive surgery, 50 patients underwent unilateral $(\mathrm{n}=14)$ or bilateral $(\mathrm{n}=36)$ MAPCA recruitment procedures. Sixty-one patients had expanded polytetrafluoroethylene modified Blalock-Taussig or end-to-side central "Mee" systemic-pulmonary shunts. Sixteen patients had undergone procedures at other institutions before referral.

\section{Surgical Algorithm}

Median age at definitive surgery was 2.0 years (interquartile range, 0.85 .5 years). Median follow-up time was 2.3 years (interquartile range, 0.16 .7 years). There were 13 early $(6 \%)$ and 13 late $(6 \%)$ deaths. Establishment of RV-PA continuity with a valved conduit and VSD closure was possible in 158 patients $(73 \%)$ : singlestage basis in 104 patients (48\%) and multiple-stage basis in 54 patients $(25 \%)$. At last follow-up, the VSD remained open in 21 patients with an RV-PA conduit. For 37 patients, the definitive procedure was PA reconstruction with systemic-pulmonary shunting without RV-PA conduit or VSD closure (Figure 1).

\section{Follow-up}

Overall survival was $89 \%$ at 3 years. Figure 2 shows the changing distribution of patients by outcome category after definitive surgery. Multifactor analysis of risk factors for survival or death performed by stepwise Cox proportional hazards regression selected only RV-PA conduit as statistically significant $(P<.05)$. Single-factor analyses for survival are shown in Table 1. 


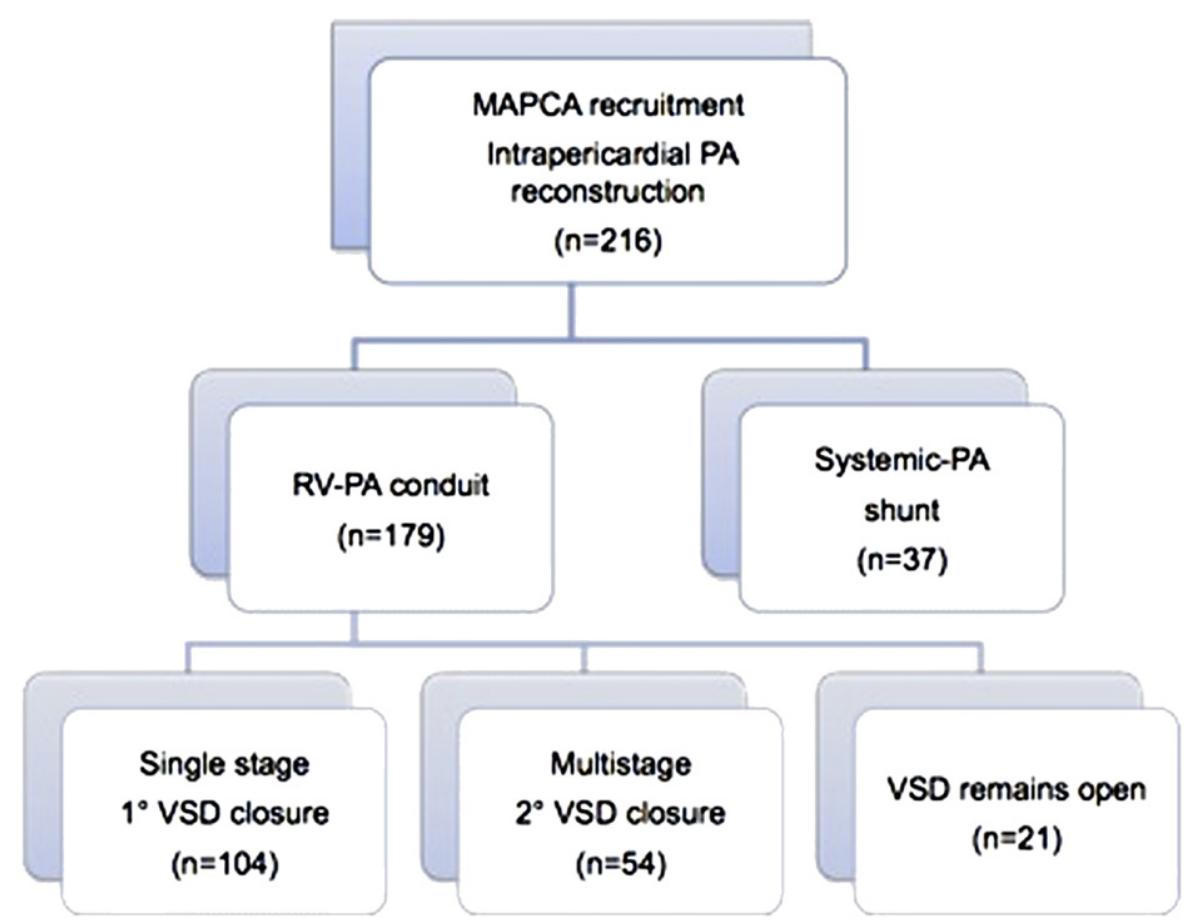

FIGURE 1. Flow chart summarizing the surgical treatment of 216 patients. MAPCA, Major aortopulmonary collateral arteries; $P A$, pulmonary artery; $R V$, right ventricle; $V S D$, ventricular septal defect.

\section{Impact of Native Pulmonary Artery Morphology}

By taking the cohort as a whole, no significant differences in the likelihood of survival were identified in patients after definitive surgery irrespective of native PA morphology (Figure 3). By comparing nonconfluent intrapulmonary and confluent intrapericardial native PAs, the 2 morphologic extremes of the spectrum, there was a nonsignificant tendency to increased risk of death in the former group (odds ratio [OR], 2.46; 95\% confidence interval [CI], $0.946 .47 ; P=.07)$ By looking closer at the subset of patients who had complete repair including RV-PA conduit and VSD closure, there were significant differences in survival in regard to native PA morphology $(P=.01)$.

\section{Achievement of Complete Repair}

As is evident from the results of survival factor analysis in Table 1, when considering factors in isolation there is little to choose between the presence of an RV-PA conduit or VSD closure as factors associated with survival, but clearly they are strongly interrelated variables. The presence of an RVPA conduit was associated with improved survival compared with systemic-pulmonary shunting alone (OR, 0.41; $95 \% \mathrm{CI}, 0.170 .97 ; P=.04)$. In all patients, VSD closure was protective against death (OR, $0.44 ; 95 \% \mathrm{CI}, 0.20$ $0.98 ; P=.04$ ) (Figure 4).

Of the 3 potential combinations of VSD and RV-PA conduit status, the results show that achieving a complete repair with a septated heart and an RV-PA conduit confers a survival advantage compared with patients with a shunted circulation with neither VSD closure nor RV-PA conduit (OR, 0.38; $95 \%$ CI, $0.160 .92 ; P=.03$ ) (Figure 5). There were no significant differences in survival between those patients who had their VSD closed on a single- or multiple-stage basis (OR, 0.57 ; 95\% CI, $0.261 .23 ; P=.15$ ) (Figure 6).

\section{Reintervention}

During the follow-up period, 190 patients underwent 196 therapeutic catheter and 60 surgical reinterventions

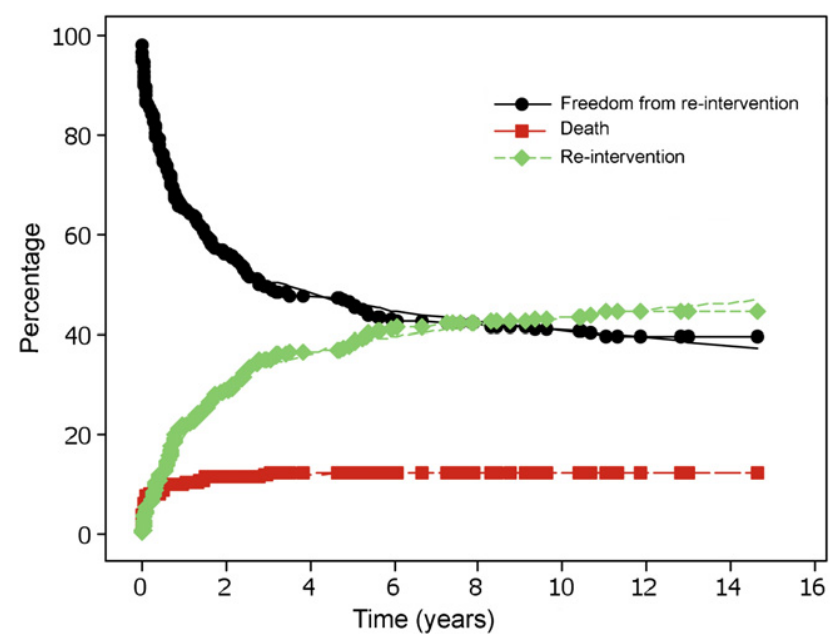

FIGURE 2. Scatter plot showing distribution of patients by outcome category after definitive surgery. 
TABLE 1. Single-factor survival analysis for death, years to death, or end of follow-up

\begin{tabular}{|c|c|c|c|c|}
\hline Factor & & OR & $95 \% \mathrm{CI}$ & $P$ value \\
\hline Age at surgery & $\mathrm{y}$ & 0.99 & $0.91 \quad 1.09$ & .92 \\
\hline Gender & Male vs female & 1.09 & $0.50 \quad 2.35$ & .83 \\
\hline DiGeorge & Yes vs no & 0.12 & $\begin{array}{ll}0.03 & 0.48\end{array}$ & .05 \\
\hline $\begin{array}{l}\text { Previous intervention } \\
\text { at other center }\end{array}$ & Yes vs no & 1.49 & 1.356 .30 & .61 \\
\hline Previous shunt & Yes vs no & 1.02 & 0.432 .43 & .96 \\
\hline Any recruitment & Yes vs no & 1.69 & 0.684 .2 & .26 \\
\hline RV PA conduit & Yes vs no & 0.41 & $\begin{array}{ll}0.17 & 0.97\end{array}$ & .04 \\
\hline \multirow{2}{*}{$\begin{array}{l}\text { VSD/RV PA conduit } \\
\text { status }\end{array}$} & Open/conduit vs open & 0.64 & 0.172 .5 & .52 \\
\hline & $\begin{array}{l}\text { Closed/conduit vs } \\
\text { open }\end{array}$ & 0.38 & 0.160 .92 & .03 \\
\hline 1 stage & 1 stage vs multistage & 0.57 & $0.26 \quad 1.23$ & .15 \\
\hline VSD closed & Closed vs open & 0.44 & 0.200 .98 & .04 \\
\hline \multirow[t]{2}{*}{ VSD by stage } & $\begin{array}{l}\text { Closed/multistage vs } \\
\text { open }\end{array}$ & 0.56 & $0.21 \quad 1.48$ & .24 \\
\hline & Closed/1 stage vs open & 0.38 & 0.150 .93 & .03 \\
\hline \multirow[t]{2}{*}{$\begin{array}{l}\text { Pulmonary atresia } \\
\text { morphologic group }\end{array}$} & $\begin{array}{l}\text { Confluent } \\
\text { intrapulmonary } \\
\text { vs confluent } \\
\text { intrapericardial }\end{array}$ & 1.53 & 0.613 .83 & .37 \\
\hline & $\begin{array}{l}\text { Nonconfluent } \\
\text { pulmonary } \\
\text { vs confluent } \\
\text { intrapericardial }\end{array}$ & 2.46 & $0.94 \quad 6.47$ & .07 \\
\hline
\end{tabular}

$O R$, Odds ratio; $C I$, confidence interval; $V S D$, ventricular septal defect; $R V$ - $P A$, right ventricle-pulmonary artery. Stepwise analysis selected only RV-PA conduit for multifactor analysis; therefore, these data are not included because the result is already in the single-factor column.

(Tables E1, E2, and E3). Ninety-one patients had at least 1 catheter, and 49 patients had further surgery, with 9 patients having more than 1 surgical reintervention. Single-factor analysis showed that definitive surgery at a younger age (OR, 0.95; 95\% CI, $0.901 .00 ; P=.05$ ) and nonconfluent intrapulmonary arteries (OR, 1.68; 95\% CI, 1.032 .73 ; $P=.04)$ were associated with increased reintervention. Only age at surgery was selected for multifactor analysis with other factors not adding extra association at the $P$ less than .05 level.

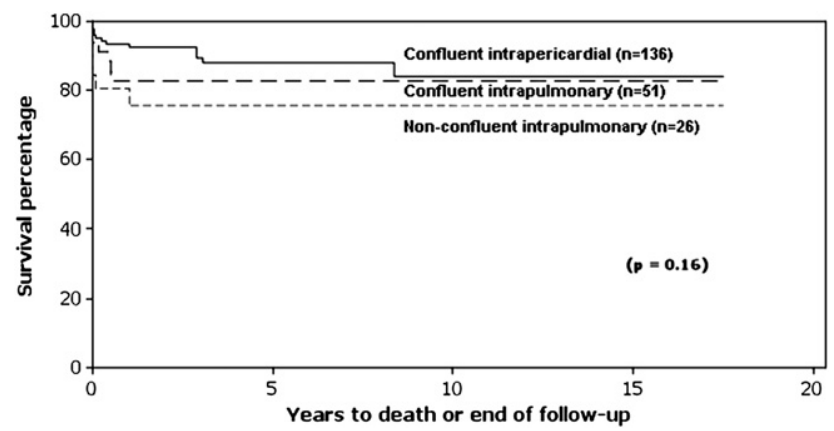

FIGURE 3. Kaplan Meier estimated survival of all patients after definitive surgery according to native PA morphology.

\section{DISCUSSION}

This work adds to the increasing body of evidence that children with pulmonary atresia VSD MAPCAs can achieve excellent outcomes by using an approach that emphasizes maximal recruitment of pulmonary vasculature and establishment of RV-PA continuity. These benefits are also applicable to those lacking intrapericardial native PAs, a subgroup who may have previously been declined surgery.

As popularized by Mee, the principle of recruiting pulmonary parenchyma by unifocalizing MAPCAs to a hilar manifold has been developed. Contemporary series using this approach in pulmonary atresia VSD have reported favorable outcomes. ${ }^{11}$ There remains, however, limited long-term follow-up data on cohorts of patients treated in this way.

\section{Assessment of Native Pulmonary Artery Anatomy}

Extensive central/intrapericardial PA reconstruction is a key feature of our approach, and we have shown that native PA morphology is not a significant determinant of death after definitive repair.

Other groups ${ }^{18}$ have used surrogates for adequacy of pulmonary blood supply, including the McGoon ratio and Nakata index, but we have not found this to be useful. ${ }^{11}$ We prefer to use a practical classification system adapted from one originally proposed by Tchervenkov and Roy. ${ }^{19}$ In our own clinical experience, we identified and classified patients into 1 of 3 groups according to intrapericardial and hilar vessels. ${ }^{11}$ We rely on subjective assessment of angiographic images and aim to recruit 1.5 lungs or 15 bronchopulmonary segments using a combination of native hilar vessels and incorporating MAPCAs where appropriate.

Initial management of the right ventricular outflow tract has evolved over time to favor reconstruction over the use of systemic-to-pulmonary shunts that others have shown to be associated with increased mortality independently of other factors. ${ }^{14,20}$ The reasons for this are unclear but may

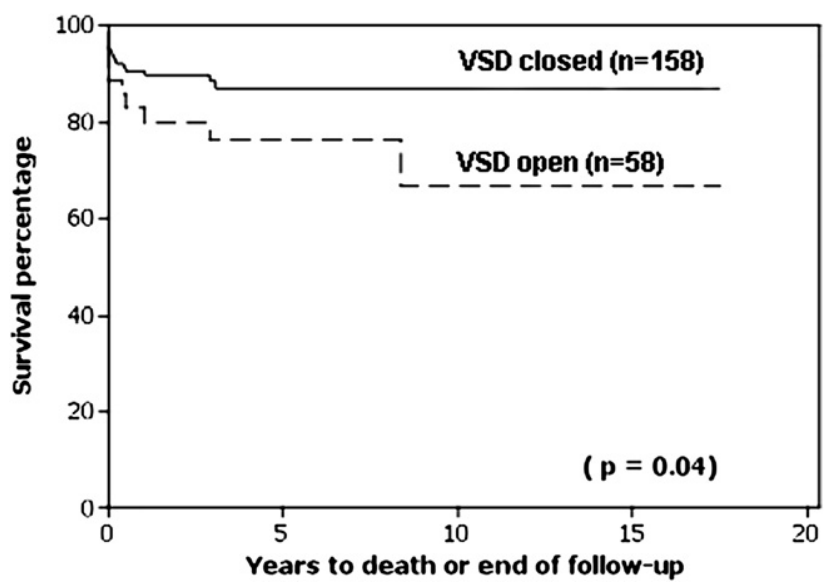

FIGURE 4. Kaplan Meier estimated survival of all patients after definitive surgery according to VSD status. VSD, Ventricular septal defect. 


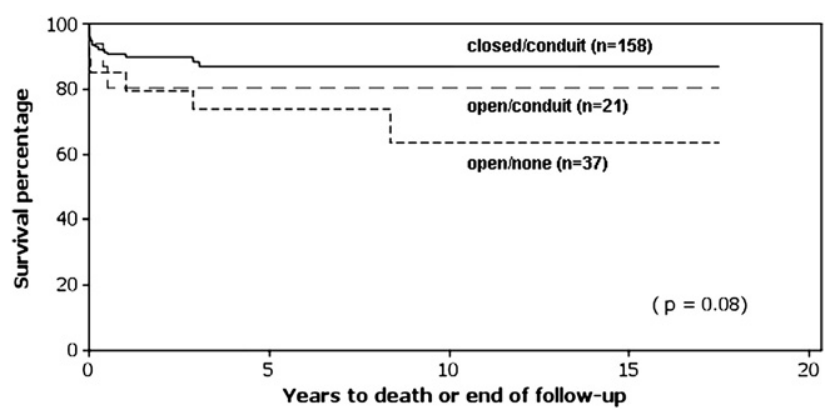

FIGURE 5. Kaplan Meier estimated survival of all patients after definitive surgery according to VSD and RV PA conduit status.

include suboptimal vascular recruitment of pulmonary parenchyma.

\section{Achievement of "Complete" Definitive Repair}

Other groups consider the natural history of MAPCAs to be sufficiently unfavorable, ${ }^{10}$ such that they avoid incorporating them into any definitive correction. However, this approach risks suboptimal segmental perfusion and depends on the optimistic hope that the native intrapulmonary vasculature will collateralize sufficiently. The assumption that MAPCAs occlude or lack growth potential is based on a review of historical angiographic images that may be flawed. ${ }^{10}$

Furthermore, advocates of an early central shunt before a "definitive" repair without incorporating MAPCAs also risk excluding a significant number of patients from what we would consider prognostically beneficial surgery. By definition, a central shunt is only possible in the presence of intrapericardial PAs, thereby excluding patients without the prerequisite luminal patency and continuity.

We believe a key determinant of long-term success is to maximize recruitment of lung segments at an early age, incorporating MAPCAs where necessary, and to establish RV-PA continuity. The current report supports this philosophy. By emphasizing intervention at an early age, problems such as stenosis and occlusion that accompany chronic exposure of MAPCAs to systemic arterial pressure can be avoided, irrespective of the vessels' embryologic origin. ${ }^{21,22}$

\section{Ventricular Septal Defect Closure Confers a Survival Advantage Irrespective of Single or Multiple Stages}

The establishment of the RV-PA continuity with a valved conduit is protective, as is VSD closure, be it on a single- or multiple-stage basis. VSD closure was undertaken by single stage in 104 patients $(48 \%)$ and multiple stages in 54 patients $(25 \%)$, and was protective (OR, $0.85 ; 95 \% \mathrm{CI}$, $0.561 .29 ; P=.56$ ) compared with leaving the VSD open. There was no significant survival advantage of single-stage VSD closure over multiple-stage closure; thus, as long as the VSD is closed, it seems not to matter if it is performed in a single stage or multiple stages. This was clarified by using a compound of the potential combinations of uni-

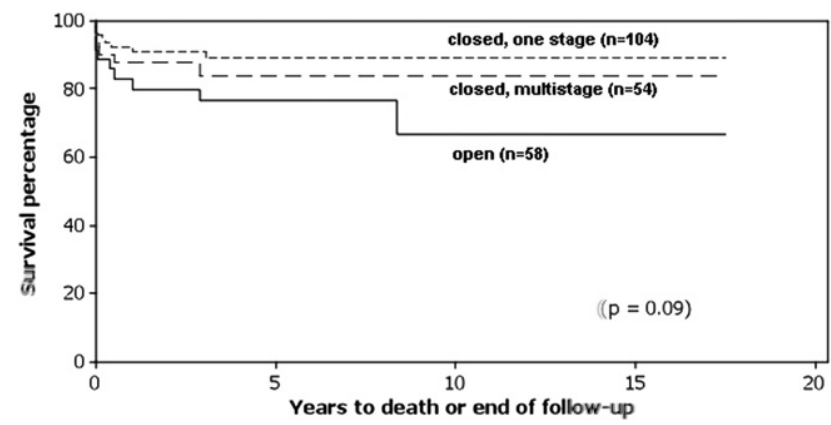

FIGURE 6. Kaplan Meier estimated survival of all patients after definitive surgery according to VSD and whether VSD closure was achieved by 1 stage or multistage repair.

focalizing a PA supply to the RV with or without VSD closure. The results demonstrate that achieving a septated heart with an RV-PA conduit had a survival advantage over a shunted circulation.

In addition, delayed VSD closure at a later stage was not associated with an increased risk of death compared with primary 1-stage repair. This lack of a significant difference in survival between groups in whom VSDs were closed initially or at a later stage is reassuring; if this step is omitted because of initial operative considerations, there does not seem to be a penalty associated with later closure.

\section{Limitations}

This is a retrospective surgical series. No accurate account could be made for patients who were reviewed but then did not subsequently undergo surgery. Unfortunately, we do not have access to exercise testing facilities to obtain an objective record of patients' functional status.

\section{CONCLUSIONS}

By using a strategy of unifocalization, intrapericardial PA reconstruction, and RV-PA conduit, excellent long-term survival can be achieved in patients with pulmonary atresia VSD MAPCAs even in the absence of native intrapericardial PAs. MAPCAs are there to be recruited, not ignored. There remains an ongoing requirement for reintervention.

The authors thank their colleagues in the Departments of Pediatric Cardiology (Drs Chikermane, Desai, Dhillon, de Giovanni, Miller, Stümper, and Wright) and Pediatric Intensive Care, Birmingham Children's Hospital for the ongoing care of these patients.

\section{References}

1. Bull K, Somerville J, Ty E, Spiegelhalter D. Presentation and attrition in complex pulmonary atresia. J Am Coll Cardiol. 1995;25:491.

2. Leonard H, Derrick G, O'Sullivan J, Wren C. Natural and unnatural history of pulmonary atresia. Heart. 2000;84:499-503.

3. Kirklin JW, Blackstone EH, Shimazaki Y, Maehara T, Pacifico AD, Kirklin JK, et al. Survival, functional status, and reoperations after repair 
of tetralogy of Fallot with pulmonary atresia. J Thorac Cardiovasc Surg. 1988;96:102-16.

4. Puga FJ, Leoni FE, Julsrud PR, Mair DD. Complete repair of pulmonary atresia, ventricular septal defect, and severe peripheral arborization abnormalities of the central pulmonary arteries. Experience with preliminary unifocalization procedures in 38 patients. J Thorac Cardiovasc Surg. 1989;98:1018-29.

5. Marelli AJ, Perloff JK, Child JS, Laks H. Pulmonary atresia with ventricular septal defect in adults. Circulation. 1994;89:243-51.

6. Haworth SG, Macartney FJ. Growth and development of pulmonary circulation in pulmonary atresia with ventricular septal defect and major aortopulmonary collateral arteries. Br Heart J. 1980;44:14-24.

7. Liao PK, Edwards WD, Julsrud PR, Puga FJ, Danielson GK, Feldt RH. Pulmonary blood supply in patients with pulmonary atresia and ventricular septal defect. J Am Coll Cardiol. 1985;6:1343-50.

8. Amin Z, McElhinney DB, Reddy VM, Moore P, Hanley FL, Teitel DF. Coronary to pulmonary artery collaterals in patients with pulmonary atresia and ventricular septal defect. Ann Thorac Surg. 2000;70:119-23.

9. Reddy VM, McElhinney DB, Amin Z, Moore P, Parry AJ, Teitel DF, et al. Early and intermediate outcomes after repair of pulmonary atresia with ventricular septal defect and major aortopulmonary collateral arteries: experience with 85 patients. Circulation. 2000;101:1826-32.

10. d'Udekem Y, Alphonso N, Norgaard MA, Cochrane AD, Grigg LE, Wilkinson JL, et al. Pulmonary atresia with ventricular septal defects and major aortopulmonary collateral arteries: unifocalization brings no long-term benefits. J Thorac Cardiovasc Surg. 2005;130:1496.

11. Griselli M, McGuirk SP, Winlaw DS, Stumper O, de Giovanni JV, Miller P, et al. The influence of pulmonary artery morphology on the results of operations for major aortopulmonary collateral arteries and complex congenital heart defects. J Thorac Cardiovasc Surg. 2004;127:251-8.

12. Brawn WJ, Jones T, Davies B, Barron D. How we manage patients with major aorta pulmonary collaterals. Semin Thorac Cardiovasc Surg Pediatr Card Surg Аппи. 2009;152-7.

13. Tchervenkov CI, Salasidis G, Cecere R, Beland MJ, Jutras L, Paquet M, et al. One-stage midline unifocalization and complete repair in infancy versus multiple-stage unifocalization followed by repair for complex heart disease with major aortopulmonary collaterals. J Thorac Cardiovasc Surg. 1997; 114:727-37.

14. Carotti A, Albanese SB, Minniti G, Guccione P, Di Donato RM. Increasing experience with integrated approach to pulmonary atresia with ventricular septal defect and major aortopulmonary collateral arteries. Eur J Cardiothorac Surg. 2003;23: 719-27.

15. Lofland GK. The management of pulmonary atresia, ventricular septal defect, and multiple aorta pulmonary collateral arteries by definitive single stage repair in early infancy. Eur J Cardiothorac Surg. 2000;18:480-6.

16. Metras D, Chetaille P, Kreitmann B, Fraisse A, Ghez O, Riberi A. Pulmonary atresia with ventricular septal defect, extremely hypoplastic pulmonary arteries, major aorto-pulmonary collaterals. Eur J Cardiothorac Surg. 2001;20:590-7.

17. Cho JM, Puga FJ, Danielson GK, Dearani JA, Mair DD, Hagler DJ, et al. Early and long-term results of the surgical treatment of tetralogy of Fallot with pulmonary atresia, with or without major aortopulmonary collateral arteries. $J$ Thorac Cardiovasc Surg. 2002;124:70-81.

18. Amark KM, Karamlou T, O'Carroll A, MacDonald C, Freedom RM, Yoo SJ, et al. Independent factors associated with mortality, reintervention, and achievement of complete repair in children with pulmonary atresia with ventricular septal defect. J Am Coll Cardiol. 2006;47:1448-56.

19. Tchervenkov CI, Roy N. Congenital Heart Surgery Nomenclature and Database Project: pulmonary atresia-ventricular septal defect. Ann Thorac Surg. 2000; 69(4 Suppl):S97-105.

20. Piehler JM, Danielson GK, McGoon DC, Wallace RB, Fulton RE, Mair DD. Management of pulmonary atresia with ventricular septal defect and hypoplastic pulmonary arteries by right ventricular outflow construction. J Thorac Cardiovasc Surg. 1980;80:552-67.

21. Norgaard MA, Alphonso N, Cochrane AD, Menahem S, Brizard CP. d'Udekem Y. Major aorto-pulmonary collateral arteries of patients with pulmonary atresia and ventricular septal defect are dilated bronchial arteries. Eur J Cardiothorac Surg. 2006;29:653-8.

22. DeRuiter MC, Gittenberger-de Groot AC, Poelmann RE, VanIperen L, Mentink MM. Development of the pharyngeal arch system related to the pulmonary and bronchial vessels in the avian embryo. With a concept on systemic-pulmonary collateral artery formation. Circulation. 1993;87: 1306-19.

\section{Discussion}

Dr Yves d'Udekem (Melbourne, Australia). We reviewed all the results with Christian Brizard, and all the comments and ques tions were discussed. What is your median time of follow up?

Dr Mussa. Three years.

Dr d'Udekem. It was actually 2.3 years in your article. And the reason for that is probably because of one of the flaws of your study. You stopped the follow up at the first intervention, which is a prob lem, because if you have an early intervention you don't know about the outcome of these patients.

In the follow up study of the Melbourne patients that we did with similar approaches, similar technique, even similar surgeons at times, we gathered a median time of follow up of 15 years. Approx imately $15 \%$ of the patients who had a definitive repair died after the repair. The median time to death was 4 years, which means half of the patients died 4 years after the repair. If your follow up is approximately 2.5 years, then you may miss half, or who knows, maybe three quarters of the deaths after repair. And having a study for which your conclusion is based solely on survival, it's a very annoying fact.

Disputes are often due to miscommunication. I think if we want to progress in that debate of MAPCAs and unifocalization, we have to clarify some terminology and in particular the term "unifocaliza tion." When you go into the lung's hilum, you dissect a confluent intrapulmonary artery, and you put a shunt there or you put a tube that you connect to the RV, I bet that you're going to call that uni focalization. I think I would call it rehabilitation of the native PAs. I think that we all agree that you have to recruit these intrapulmonary native PAs. But the real question is, what happened to the collateral arteries that you detach from the aorta and incorporate in that pul monary arborization?

Do you have an idea of what proportion of patients underwent translocation of collateral arteries; and if you know that, do you have angiographic control studies of these translocated collateral arteries?

Dr Mussa. Well, you remember from our presentation that we had reintervened on approximately all of our patients. But in terms of reintervention on the MAPCAs, there weren't many. Like I said, only 1 stent and 2 balloons. There were some surgical interventions of the proximal portions of those, but I don't know the exact num bers of those, but we intervened on approximately 30 main PAs.

Dr d'Udekem. I'm afraid it's difficult to reintervene on a collat eral if it's not existent anymore; that's my concern and why I think we need to have these angiographic data.

In your conclusion, I quote, you said, "MAPCAs are there to be recruited.' We thought that was a very firm statement expressed like that. We have looked at your results, and we thought there may be some problems with that statement.

First, as I mentioned, the conclusion is based on survival, and we're not sure exactly yet about the survival. It may be excellent, but I think that remains to be demonstrated.

Second, you may want to use more equipoise in the interpreta tion of your results. For example, if you look at the characteristics of your patients, by the end of the study you have 50 of 216 patients left with a palliation. I think that's an important proportion. You may as well conclude in your study that you achieve a good survival in these patients if you leave a lot of them palliated. Or if you have only collateral translocations in, I don't know, 5060 patients, which 
I guess it is, you can say, okay, you have better survival if you rehabilitated native PAs. Obviously these are just suggestions.

I'm wondering if these patients are not sicker than they appear to be, and, especially about what you say, they have a high rate of in tervention, $80 \%$ reintervention at 5 years. So I'm sure you don't do unnecessary reintervention. So one can suspect that a lot of these patients may have elevated right ventricular to left ventricular pres sure ratio, and I think that question should be solved.

There were angiographies for every single one of those undergo ing these 196 reinterventions. It is difficult to show that translocated collateral arteries disappear. It might be much easier to demonstrate angiographically that these translocated collateral arteries remain patent. So if that is the case, it should be relatively easy to show an giograms with beautiful pulmonary arborization after translocation of the collateral arteries.

Do you have further data analysis or further evidence, particu larly angiographic, to substantiate the statement that "MAPCAs are there to be recruited," or do you want to soften up a little bit that statement?

Dr Mussa. I'll start with the RV LV pressure ratio that you asked about first. Certainly that's an excellent question. It's data that we are looking at, and we have yet to come to a conclusion as to what our RV LV pressure ratios are doing over time.

In terms of angiographic follow up to examine the MAPCAs that we have recruited, unfortunately, a lot of our patients are lo cated all over Europe, and it's difficult to get angiographic data on all of those patients to see exactly how those MAPCAs have fared over time. So I'm sorry, we don't have that data.

Dr Frank Hanley (Stanford, Calif). Congratulations on a phe nomenal series of patients. Just to weigh in on this question of whether MAPCAs are valuable or not, we have an approximate
$21 \%$ incidence of completely absent intrapericardial PAs, meaning not a string like, not even a cord like structure, but completely ab sent, including absence of confluent hilar areas. That $21 \%$ inci dence translates into more than 100 patients with unifocalized vessels and no intrapericardial PAs. With 8 year mean follow up, and follow up up to 15 years, that subgroup is no different than the larger population. So it doesn't play out as a risk factor for either RV LV pressure ratio or survival.

The important message is, if patients can survive up to 15 years after unifocalization and repair when there were no true PAs, only collaterals, with the same outcome as those who have true PAs, it is unequivocal that collaterals are of value. This is the case when there are absent PAs. It follows that collaterals will be of benefit in any case where the PAs, if present, do not arborize normally.

Dr Mussa. Thank you.

Dr James Tweddell (Milwaukee, Wis). Among the patients who were unifocalized and in whom the VSD was left open, you used 2 strategies to supply pulmonary blood flow, an RV PA conduit or a Blalock Taussig shunt. How did you make that decision? And within that group, did you notice any difference in the likelihood of subsequent VSD closure between those 2 strategies?

Dr Mussa. First, I would just say that of those patients with the VSD left open and the use of the Blalock Taussig shunt, the use of shunts was largely historical in this series and was performed early on more than now. Can I just get your second question again, please?

Dr Tweddell. Among those 2 strategies of supplying pulmonary blood flow in the patients whose VSDs were open, did you identify a difference in the likelihood of subsequent VSD closure between those 2 strategies?

Dr Mussa. The simple answer is no, we didn't. 
TABLE E1. Single-factor survival analysis for years to intervention, death, or end of follow-up

\begin{tabular}{|c|c|c|c|c|}
\hline Factor & & OR & $\mathbf{9 5} \% \mathrm{CI}$ & $P$ value \\
\hline Age at surgery & $\mathrm{y}$ & 0.95 & $0.9-1.00$ & .05 \\
\hline Gender & Male vs female & 1.01 & $0.71-1.45$ & .93 \\
\hline DiGeorge & Yes vs no & 1.28 & $0.76-2.18$ & .35 \\
\hline $\begin{array}{l}\text { Previous intervention } \\
\text { at other center }\end{array}$ & Yes vs no & 0.64 & $0.26-1.58$ & .33 \\
\hline Previous shunt & Yes vs no & 1.16 & $0.78-1.74$ & .46 \\
\hline Previous recruitment & Yes vs no & 1.02 & $0.63-1.66$ & .94 \\
\hline RV-PA conduit & Yes vs no & 1.00 & $0.63-1.60$ & .99 \\
\hline \multirow[t]{2}{*}{ VSD by conduit } & Open/conduit vs open & 1.27 & $0.60-2.71$ & .53 \\
\hline & $\begin{array}{l}\text { Closed/conduit vs } \\
\text { open }\end{array}$ & 0.93 & $0.56-1.54$ & .77 \\
\hline One stage & 1 vs multistage & 0.90 & $0.63-1.29$ & .56 \\
\hline VSD closed & Closed vs open & 0.85 & $0.56-1.29$ & .56 \\
\hline \multirow[t]{2}{*}{ VSD by stage } & Closed/multi vs open & 1.12 & $0.69-1.82$ & .65 \\
\hline & Closed/1 stage vs open & 0.73 & $0.47-1.15$ & .18 \\
\hline \multirow[t]{2}{*}{ Group } & $\begin{array}{l}\text { Confluent } \\
\text { intrapulmonary } \\
\text { vs confluent } \\
\text { intrapericardial }\end{array}$ & 1.10 & $0.73-1.68$ & .63 \\
\hline & $\begin{array}{l}\text { Nonconfluent } \\
\text { intrapulmonary } \\
\text { vs confluent } \\
\text { intrapericardial }\end{array}$ & 1.68 & $1.03-2.73$ & .04 \\
\hline
\end{tabular}

$O R$, Odds ratio; $C I$, confidence interval; $V S D$, ventricular septal defect; $R V-P A$, right ventricle-pulmonary artery. Only age at surgery was selected for multifactor analysis in stepwise Cox proportional hazards regression; thus, these data are not shown. The other factors did not add extra association at the $P<.05$ level.
TABLE E3. Individual components of surgical reoperations $(n=60)$

\begin{tabular}{lc} 
& n \\
\hline RV-PA conduit change & 35 \\
PA augmentation & 30 \\
VSD closure & 54 \\
Further MAPCA recruitment & 3 \\
Pulmonary artery band & 2 \\
Resection of obstructive & 1 \\
$\quad$ infundibular muscle bar & \\
Repair of RV-PA conduit & 1 \\
$\quad$ false aneurysm & \\
$R V-P A$, Right ventricle-pulmonary artery; $V S D$, ventricular septal defect; $M A P C A$ & \\
major aortopulmonary collateral arteries.
\end{tabular}

TABLE E2. Catheter reinterventions $(n=196)$

\begin{tabular}{lc}
\hline & $\mathbf{n}$ \\
\hline Pulmonary artery balloon dilatation & 145 \\
Pulmonary artery stent & 11 \\
MAPCA balloon dilatation & 2 \\
MAPCA stent & 1 \\
MAPCA embolization & 12 \\
Balloon dilatation conduit & 2 \\
Pacemaker & 5 \\
Stenting of systemic-pulmonary shunt & 1 \\
Dilatation of fenestrated VSD patch & 1 \\
\hline
\end{tabular}

$M A P C A$, Major aortopulmonary collateral arteries; $V S D$, ventricular septal defect. 